\title{
The cardiovascular profile of soccer referees: an echocardiographic
} study

\author{
G Galanti*1, A Pizzi², M Lucarelli2 ${ }^{2}$ L Stefani ${ }^{1}$, M Gianassi ${ }^{1}$, V Di Tante1, \\ L Toncelli $^{1}$, A Moretti ${ }^{1}$ and F Del Furia ${ }^{1}$
}

\begin{abstract}
Address: ${ }^{1}$ Postgraduate School of Sports Medicine, Sports Medicine Laboratory Dept Emergency Medicine, University of Florence, Italy and ${ }^{2}$ FIGC Federazione Italiana Gioco Calcio - AIA Associazione Italiana Arbitri, Italy

Email: G Galanti* - g.galanti@dac.unifi.it; A Pizzi - pizzia@libero.it; M Lucarelli - aia.preatletica@fgc.it; L Stefani - laura-stefani@tiscali.it; M Gianassi - gianassi.marco@libero.it;V Di Tante - vditante@yahoo.it; L Toncelli - toncellil@libero.it; A Moretti - dott.andreamoretti@libero.it; F Del Furia - F.delfuria@libero.it

* Corresponding author
\end{abstract}

Published: 12 February 2008

Cardiovascular Ultrasound 2008, 6:8 doi:10.1 186/1476-7/20-6-8
Received: 20 November 2007

Accepted: 12 February 2008

This article is available from: http://www.cardiovascularultrasound.com/content/6/I/8

(c) 2008 Galanti et al; licensee BioMed Central Ltd.

This is an Open Access article distributed under the terms of the Creative Commons Attribution License (http://creativecommons.org/licenses/by/2.0), which permits unrestricted use, distribution, and reproduction in any medium, provided the original work is properly cited.

\begin{abstract}
Background: During a soccer game, the cardiovascular system is severely taxed The referees must be alert and their level of fitness must be such that fatigue will not impair their decisionmaking. Referee's peak overall performance is usually after 40 when the performance starts to decline. We evaluated the morphological and functional cardiac profile of professional soccer referees.
\end{abstract}

Materials and methods: We submitted to a clinical and echocardiographic exam a group of I 20 professional soccer referees aged $25-45$ years, including the first division of the Italian Championship, matched with 120 soccer players, including élite soccer players. Data were compared using an unpaired Student's $t$ test. Statistical significance was with $p<0.05$.

Results: Right ventricle dimensions ( $22.2 \pm 3.8$ vs $25.9 \pm 2.4 \mathrm{~mm}$ ) and Left Ventricular Mass Index (LVMi) $(100.5 \pm 45.2$ vs $105.4 \pm 17.3)$ were significantly greater in referees than in active soccer players. Left atrium dimensions ( $33.7 \pm 8.9 \mathrm{vs} 36.2 \pm 3.1 \mathrm{~mm})$, aortic root $(29.7 \pm 7.9$ vs $32.1 \pm 3$ $\mathrm{mm})$ and LVMi $\left(\mathrm{I} 15 . \mathrm{I} \pm 16.7 \mathrm{vs} 134 . \mathrm{I} \pm 19.9 \mathrm{~g} / \mathrm{m}^{2}\right)$ were significantly greater in élite soccer players than in first-division referees.

Conclusion: Our investigation shows that right ventricle is greater in referees than in soccer players. The differences (left atrium, aortic root and LVMi) between first division referees and élite soccer players may derive from the different training workloads.

\section{Introduction}

During a soccer game the cardio-circulatory system is severely taxed [1], and soccer referees need to have high levels of physical fitness. To referee a soccer game, they must be alert and near the scene of action, and their level of fitness must be such that fatigue will not impair their decision-making. Referees are often subjected to proportionally increasing physical demands as years go by. Indeed, their peak performance is usually between 30 and 45 years of age, when cardiovascular athletic performance starts to decline. Several studies have investigated the athletic performance of referees [2-4] The aim of our study is 
to evaluate the morphological and functional cardiac profiles of professional soccer referees.

\section{Methods}

Subjects

We examined 120 professional Italian soccer referees from the Italian Association of Referees, 35 officiated in firstdivision, aged between 25 and 45 years, over the period $7^{\text {th }}$ to $15^{\text {th }}$ July 2006 , before the start of the soccer season.

The referees were compared with 120 soccer players (35 élite soccer players from the first division) examined at the Sports Medicine Centre of the University of Florence. Furthermore, first-division referees were matched with firstdivision soccer players.

Referees generally train 3-4 times/week and soccer players 5-6 times.

The qualities which are mainly worked on are: aerobic power, strength, sprint resistance (the athlete runs at a velocity $>23 \mathrm{~km} / \mathrm{h}$ and for a distance $<50 \mathrm{~m}$ ), speed (velocity $>23 \mathrm{~km} / \mathrm{h}$ and distance $<30 \mathrm{~m}$ ). Table $1-2$.

All procedures described in the present study were approved by our Local Ethics Committee.

\section{Clinical evaluation}

All referees and players underwent a general clinical examination, which included history- taking, a general clinical check-up, and a cardiological examination consisting of echocardiography and ECG at rest.

\section{Echocardiography}

Each subject was examined in the morning after an overnight fast with mono-bidimensional echocardiographic and Doppler tests. The end-systolic and end-diastolic left ventricle diameters, interventricular septum and posterior wall thickness, left atrium and aorta with efflux tract measures were obtained with $M$-mode view starting from the long parasternal axis, and B- mode view according to the American Society of Echocardiography [5]. Fig. 1-2.

Table I: First-division soccers' training sessions

\begin{tabular}{lcc}
\hline FD Soccers & $\begin{array}{c}\text { Number/YEAR } \\
\text { Mean Standard Deviation }\end{array}$ & $\begin{array}{c}\text { Number/WEEK } \\
\text { Mean }\end{array}$ \\
\hline Training sessions & $296 \pm 10$ & 5.6 \\
Aerobic power & $73 \pm 9$ & 0.8 \\
Strength & $84 \pm 12$ & 2.1 \\
Speed & $77 \pm 6$ & 1.2 \\
Sprint resistance & $69 \pm 4$ & 1.3 \\
\hline
\end{tabular}

Table 2: First division referees players' training sessions

\begin{tabular}{lcc}
\hline FD Referees & $\begin{array}{c}\text { Number/YEAR } \\
\text { Mean } \pm \text { Standard Deviation }\end{array}$ & $\begin{array}{c}\text { Number/WEEK } \\
\text { Mean }\end{array}$ \\
\hline Training sessions & $125 \pm 14$ & 3.6 \\
Aerobic power & $40 \pm 6$ & 1 \\
Strength & $35 \pm 9$ & 1 \\
Speed & $30 \pm 7$ & 0.9 \\
Sprint resistance & $27 \pm 5$ & 0.8 \\
\hline
\end{tabular}

Left Ventricular Mass Index (LVMI) was calculated according to Devereux and Reichek [6]

using the formula:

$$
\operatorname{LVM}=\left[0.80 \times 1.05 \times(\mathrm{IVS}+\mathrm{PW}+\mathrm{Vsxd})^{3}-\mathrm{Vsxd}^{3}\right)
$$

Where:

- LVM = left ventricular mass in gr.

- IVS = measure of interventricular septum

- PW = measure of posterior wall

- Vsxd = left ventricular end-diastolic diameter.

The LVM value was normalized for body surface $\left(\mathrm{g} / \mathrm{m}^{2}\right)$. Diastolic function was evaluated with Doppler measurements on transmitral flow, and included E (early) and A (Atrial) peak mitral velocities, isovolumetric relaxation (IVR), and E/A ratio. All these variables were recorded from the four-chamber view[7].

\section{Statistical Analysis}

Values were expressed as average \pm standard deviation. Data were compared using an unpaired Student's t test. A $p$ value of $<0.05$ was considered statistically significant

\section{Results}

Referees versus soccer players

No significant differences between referees and soccer players were found in: aortic root diameter, left ventricular diastolic dimension, left ventricular diastolic dimension, septum, posterior wall thickness. Left ventricular mass index $\left(105.1 \pm 19.3 \mathrm{~g} / \mathrm{m}^{2} \mathrm{vs} 100.1 \pm 45.2 \mathrm{~g} / \mathrm{m}^{2}\right)$, and right ventricle dimensions $(22.2 \pm 3.8 \mathrm{~mm}$ vs $25.9 \pm 2.4$ $\mathrm{mm}$ ) were significantly greater in referees, left atrial dimensions $(33.9 \pm 7.4 \mathrm{~mm}$ vs $36.5 \pm 4.5 \mathrm{~mm})$ were greater in soccer players. Referees were significantly taller than soccer players. (Table 3, Fig. 1) 


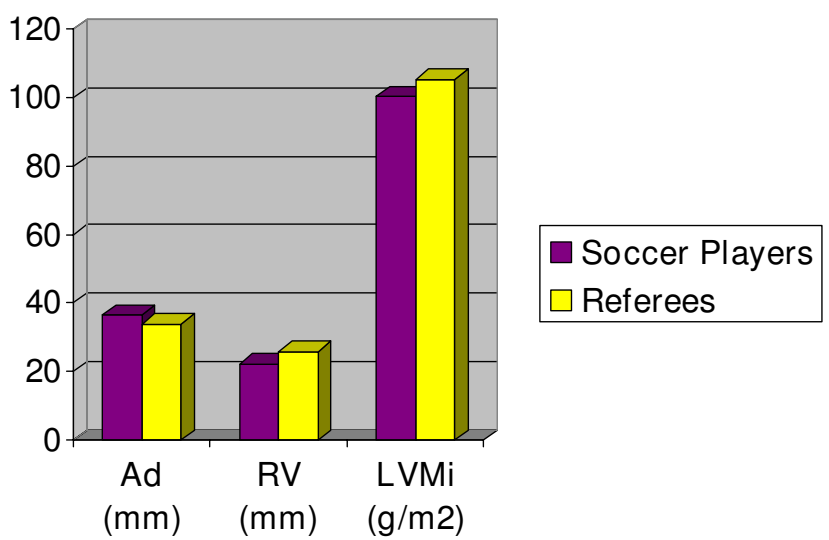

Figure I

Histogram summarizing the echo-findings of the study "referees vs soccer players". AD : Atrial Dimension; RV: Right Ventricle; LVMi: Left Ventricle Mass Index.

First-division referees versus first-division soccer players The dimensions of the left atrium $(33.7 \pm 8.9$ vs $36.2 \pm$ $3.1)$, aortic root $(29.7 \pm 7.9$ vs $32.1 \pm 3)$ and LVMI (115.1 \pm 16.7 vs $134.1 \pm 19.9)$ were significantly greater in the soccer players than in referees. No differences in diastolic function were found between these two groups. Referees were significantly taller than soccer players. (Table 4, Fig. 2)

\section{Discussion}

Long-term athletic training is associated with morphological cardiac changes, including increased left ventricular cavity dimension, wall thickness, and calculated mass, which are commonly described as "athlete's heart".

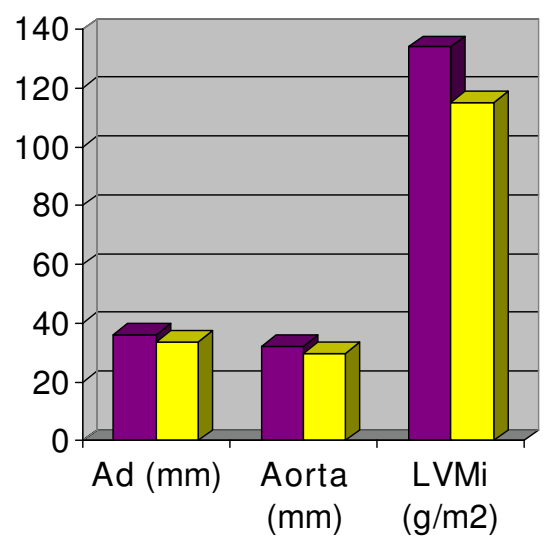

FD soccer players

$\square$ FD Referees

\section{Figure 2}

Histogram summarizing the echo-findings of the study in the two groups "FD referees vs FD soccer players". FD : First Division; AD : Atrial Dimension; RV: Right Ventricle; LVMi: Left Ventricle Mass Index
Table 3: Soccer players and referees

\begin{tabular}{lll}
\hline General data & Soccers $N=120$ & Referees $N=120$ \\
\hline Age $($ years $)$ & $25.0 \pm 13.0$ & $32.0 \pm 3.3$ \\
Height $(\mathrm{cm})$ & $172.5 \pm 10.5^{*}$ & $184 \pm 5.7 *$ \\
Weight $(\mathrm{Kg})$ & $65 \pm 10.0$ & $77.2 \pm 6.6$ \\
HR $(\mathrm{bpm})$ & $72.2 \pm 12.6$ & $59.4 \pm 13.5$ \\
SBP $(\mathrm{mmHg})$ & $119.5 \pm 10.4$ & $120.7 \pm 13.2$ \\
DBP $(\mathrm{mmHg})$ & $76.0 \pm 5.0$ & $73.1 \pm 10.2$ \\
Echocardiographic data & & \\
Ad $(\mathrm{mm})$ & $36.5 \pm 4.5^{*}$ & $33.9 \pm 7.4^{*}$ \\
IVS $(\mathrm{mm})$ & $9.8 \pm 1.2$ & $9.4 \pm 0.6$ \\
PWT $(\mathrm{mm})$ & $9.6 \pm 1.4$ & $9.1 \pm 0.6$ \\
Aorta $(\mathrm{mm})$ & $30.6 \pm 4.4$ & $29.6 \pm 6.6$ \\
RV $(\mathrm{mm})$ & $22.2 \pm 3.8^{*}$ & $25.9 \pm 2.4 *$ \\
LVDD $(\mathrm{mm})$ & $50.7 \pm 3.3$ & $52.5 \pm 3.5$ \\
LVDS $(\mathrm{mm})$ & $31.0 \pm 3.0$ & $32.5 \pm 2.8$ \\
E peak $(\mathrm{m} / \mathrm{sec})$ & $80.0 \pm 15.0$ & $80.9 \pm 24.1$ \\
A peak $(\mathrm{m} / \mathrm{sec})$ & $40.0 \pm 15.0$ & $48.4 \pm 14.5$ \\
IVR $(\mathrm{msec})$ & $79.1 \pm 14.8$ & $68 \pm 26.2$ \\
DT $(\mathrm{msec})$ & $192.5 \pm 40.1$ & $171.6 \pm 54.5$ \\
LVM $(\mathrm{g})$ & $179.6 \pm 81.4^{*}$ & $211.4 \pm 37 . I^{*}$ \\
LVMi $\left(\mathrm{g} / \mathrm{m}^{2}\right)$ & $100.5 \pm 45.2^{*}$ & $105.4 \pm 17.3^{*}$
\end{tabular}

HR heart rate, SBP systolic blood pressure, DBP diastolic blood pressure, Ad atrial dimension, IVS interventricular septum, PWT posterior wall thickness, RV right ventricle, LVDD left ventricular diastolic dimension, LVDS left ventricular systolic dimension, LVMi left ventricular mass index; *Significant difference according to Student's $t$ test $p<0.05$

These changes seem to be adaptations to the hemodynamic load produced by long-term, frequent, intensive exercise programs. Our investigation shows that referees'

Table 4: First-division soccer players and first-division referees

\begin{tabular}{lll}
\hline General data & FD Soccers $\mathrm{N}=35$ & FD referees $\mathrm{N}=35$ \\
\hline Age $($ years $)$ & $28.0 \pm 6.7$ & $34.3 \pm 3.4$ \\
Height $(\mathrm{cm})$ & $180.8 \pm 6.3^{*}$ & $184 \pm 7.6^{*}$ \\
Weight $(\mathrm{Kg})$ & $78.8 \pm 6.8$ & $76.3 \pm 8.2$ \\
HR $(\mathrm{bpm})$ & $59.3 \pm 8.6$ & $61.7 \pm 16.9$ \\
SBP $(\mathrm{mmHg})$ & $120.5 \pm 2.8$ & $121.8 \pm 13.0$ \\
DBP $(\mathrm{mmHg})$ & $75.9 \pm 4.5$ & $71.2 \pm 13.7$ \\
Echocardiographic data & & \\
Ad $(\mathrm{mm})$ & $36.2 \pm 3.1^{*}$ & $33.7 \pm 8.9^{*}$ \\
IVS $(\mathrm{mm})$ & $10.6 \pm 0.8$ & $9.78 \pm 0.6$ \\
PWT $(\mathrm{mm})$ & $10.2 \pm 0.8$ & $9.24 \pm 0.6$ \\
Aorta $(\mathrm{mm})$ & $32.1 \pm 3^{*}$ & $29.7 \pm 7.9^{*}$ \\
RV $(\mathrm{mm})$ & $24.7 \pm 3.9$ & $26.1 \pm 2.5$ \\
LVDD $(\mathrm{mm})$ & $54.8 \pm 3.2$ & $54.2 \pm 3.5$ \\
LVDS $(\mathrm{mm})$ & $34.1 \pm 2.4$ & $32.8 \pm 2.7$ \\
E peak $(\mathrm{m} / \mathrm{sec})$ & $74.8 \pm 13.1$ & $80.4 \pm 30.2$ \\
A peak $(\mathrm{m} / \mathrm{sec})$ & $41.7 \pm 11.2$ & $48.4 \pm 11.7$ \\
IVR $(\mathrm{msec})$ & $75.8 \pm 11.6$ & $63.9 \pm 22.6$ \\
DT $(\mathrm{msec})$ & $187.5 \pm 35.9$ & $157.4 \pm 35.9$ \\
LVM $(\mathrm{g})$ & $268.5 \pm 40.4$ & $231 \pm 37.1$ \\
LVMi $\left(\mathrm{g} / \mathrm{m}^{2}\right)$ & $134.1 \pm 19.9^{*}$ & $115.1 \pm 16.7^{*}$ \\
& &
\end{tabular}

FD first division, HR heart rate, SBP systolic blood pressure, DBP diastolic blood pressure, Ad atrial dimension, IVS interventricular septum, PWT posterior wall thickness, RV right ventricle, LVDD left ventricular diastolic dimension, LVDS left ventricular systolic dimension, LVMi left ventricular mass index; *Significant difference according to Student's t test $p<0.05$ 
hearts present an increase in left ventricular mass and normal systolic and diastolic function, similar to that in soccer players. Thus a referee's heart can also be considered a physiological athlete's heart $[8,9]$.

These morphological and functional modifications may be due to the fact that during the match and weekday training the work load is sufficiently intense to cause an increase in left ventricular mass, and morphological and functional modifications in the heart over the long term.

During a match in fact, a referee covers a distance of between 7000 and 10000 meters at an average heart rate of 150 to $160 \mathrm{bpm}$ and an average oxygen uptake of approximately $80 \%$ of the maximum aerobic power. $[10,11]$

Elite soccer referees usually reach the peak of their careers at a considerably greater average age than competitive soccer players. Thus, referees perform best physically at a time when their cardiovascular performances start to decline.

So even if referees are older than soccer players, our echocardiographyc study shows how the referee's heart presents morphological adaptations like soccer, including similar parameters and an increase in left ventricular mass (both due to the training work load). For this reason the referee's cardiovascular adaptations allow the same soccer's players performance

The differences between first-division referees and elite soccer players may result from the different workloads undergone during both match and training. In fact, during an official match, soccer players cover a distance of between 8 and $12 \mathrm{~km}$, with a speed of between 10 to 19 $\mathrm{Km} / \mathrm{h}$, but their training load during the week is usually five days of training sessions plus the official match. The soccer players usually underwent training with a predominant increase in both volume endurance and pressure resistance exercise, while the referees mainly practiced endurance training [13].

This observation may explain the morphological differences between the players' and referees' left ventricular mass.

The present results are in partial disagreement with those of Castagna et al. $[14,15]$, who studied the performances of referees of different age-groups and reported no differences in the 12-minute running test, whereas speed and acceleration tests were significantly better in the younger referees. However, the focus of the present investigation is on cardiac morphology at rest and systolic and diastolic function.
Finally, general performance in athletes is due not only to the contractile function of the heart, but also to complex interactions with the neurological and muscle-skeletal systems.

Our unpublished personal data on élite soccer players (ACF Fiorentina Football Team) have in fact showed that functional performances differed even among players whose cardiac mass was equal. The athletes followed the same training program.

\section{Conclusion and limitations of the study}

This investigation has focused exclusively on cardiac morphology, and thus presents no functional correlation with maximum oxygen consumption and endurance, speed and strength performances.

Athletes between 35 and 40 years can maintain a good performance in both short- and long- distance running. However, even if these important parameters progressively decrease with age, with peak decrease occurring at about 50 years, performance is not dramatically impaired when the athlete is 40 years old. $[16,17]$.

These results are supported in the literature by the study of Rotoyannis and Korhonem, who demonstrated that 3540 year-old athletes are able to maintain good performance in marathon runs up to $50 \mathrm{Km}$, or sprints up to 100 $\mathrm{m}[18-21]$

Finally, it would be interesting to conduct a longitudinal study on referees entering the first division. It is in fact important that a referee's physical performance should not decrease, in order also to guarantee the psychological aspects of refereeing, which are certainly improved with specific experience within the sporting context.

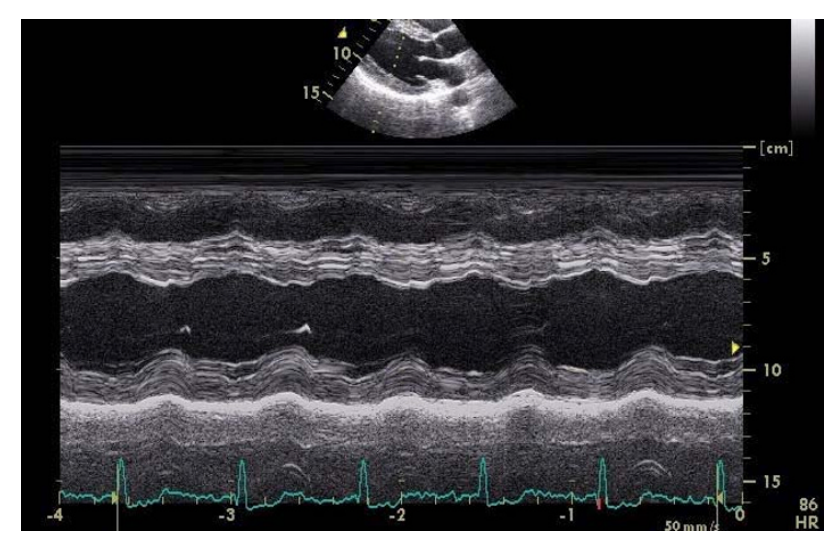

Figure 3

Soccer player 's 2D-targeted M-mode tracing. 


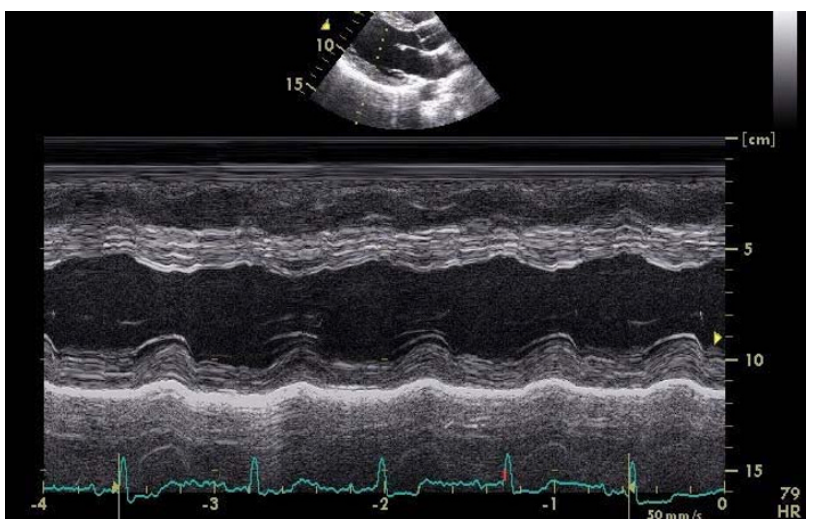

Figure 4

Referee's 2D-targeted M-mode tracing.

\section{Competing interests}

The author(s) declare that they have no competing interests.

\section{Authors' contributions}

The initial idea for the study was of GG. GG, AP, ML, LS and AM designed the study, and GG, LS, LT and AM performed all the measurements and statistical analyses. GG wrote the manuscript and all the authors contributed to, read, and approved the final version.

\section{Acknowledgements}

We wish to thank Susan Charlton for her revision of the English manuscript

\section{References}

I. Reilly T, Gregson W: Special populations: the referees and assistant referees. J Sports Sci 2006, 24(7):795-80I.

2. Castagna C, D'Ottavio S: Effect of maximal aerobic power on match performance in elite soccer referees. J Strength Cond Res 200I, I5(4):420-5.

3. Stolen T, Chamari K, Castagna C, Wisloff U: Physiology of soccer: an update. Med 2005, 35(6):50I-36.

4. Di Salvo V, Baron S, Tschan H, Calderon Montero FJ, BachI N, Pigozzi F: Performance characteristic according to playing position in elite soccer. Int / Sports Med 2006 in press.

5. Cheitlin MD, Armstrong WF, Aurigemma GP, Beller GA, Bierman FZ, Davis JL, Douglas PS, Faxon DP, Gillam LD, Kimball TR, Kussmaul WG, Pearlman AS, Philbrick JT, Rakowski H, Thys DM, Antman EM, Smith SC Jr, Alpert JS, Gregoratos G, Anderson JL, Hiratzka LF, Faxon DP, Hunt SA, Fuster V, Jacobs AK, Gibbons RJ, Russell RO: ACC/ AHA/ASE 2003 Guideline update for the clinical application of echocardiography : A report of the American College of Cardiology, American Heart Association task force on practise guidelines. J Am Soc Echocardiography 2003, 10:1091-I I0.

6. Devereux RB: Detection of left ventricular hypertrophy by $M$ mode echocardiography. Anatomic validation, standardization and comparison to other methods. Hypertension 1987, 20:125I-60.

7. Nishimura RA, Tajik AJ: Evaluation of diastolic filling of the left ventricle in health and disease: Doppler echocardiography is the clinician's Rosetta Stone. J Am Coll Cardiol I997, 30(I):8- I8.

8. Pelliccia A, Maron BJ, Spataro A, Proschan MA, Spirito P: The upper limit of physiologic cardiac hypertrophy in highly trained elite athletes. N Engl J Med I99I, 324:295-30I.
9. Pelliccia A, Culasso F, Di Paolo F, Maron BJ, et al.: Physiologic left ventricular cavity dilatation in elite athletes. Ann Intern Med 1990, 130:23-31.

10. Castagna C, Abt G, D'Ottavio S: Activity profile of internationallevel soccer referees during competitive match. J Strength Cond Res 2004, 18:486-90.

II. D'Ottavio S, Castagna C: Physiological load imposed on elite soccer referees during actual match play. J Sports Med Phys Fitness 200I, 4I:27-32.

12. Krustrup P, Bangsbo J: Physiological demands of top-class soccer refereeing in relation to physical capacity: effect of intense intermittent exercise training. J Sports Sci 200I, 19:88I-9I.

13. Di Salvo V, Baron S, Tschan H, Calderon Montero FJ, Bachl N, Pigozzi F: Performance characteristics according to playing position in elite soccer. Int J Sports Med 2007, 28(3):222-7. 2006, Oct 6

14. Castagna C, Abt G, D'Ottavio S, Weston M: Age-related effects on fitness performance in elite-level soccer referees. J strength Cond Res 2005, 19:785-90.

15. Korhonen MT, Mero A, Suominen H: Age related differences in 100-m sprint performance in male e female master runners. Med Sport Sci Exe 2003, 35:1419.

16. Rontoyannis G: Sixty-three years of competitive sport activity. Case Study. J Sports med Phys Fitness 1992, 32(3):332-9.

17. Rosen MJ, Sorkin JD, Goldberg AP, Hagberg JM, Katzel LI: Predictors of age-associated decline in maximal aerobic capacity: a comparison of four statistical models. J Appl Physiol 1998, 84:2163.

18. Hagerman FC, Fielding RA, Fiatarone MA, Gault JA, Kirkendall DT, Ragg KE, Evans W]: A 20-yr longitudinal study of Olympic oarsmen. Med Sci Sports Exerc 1996, 28: II 50.

19. Jackson AS, Wier LT, Ayers GW, Beard EF, Stuteville JE, Blair SN: Changes in aerobic power of women, ages 20-64 yr. Med Sci Sports Exerc 1996, 28:884.

20. Kasch FW: The effect of physical activity and inactivity on aerobic power in older men (a longitudinal study). Phys Sportsmed 1990, 18:73.

2I. Pollock ML, Foster C, Knapp D, Rod JL, Schmidt DH: Effect of age and training on aerobic capacity and body composition of master athletes. J Appl Physiol 1987, 62(2):725-31.
Publish with Bio Med Central and every scientist can read your work free of charge

"BioMed Central will be the most significant development for disseminating the results of biomedical research in our lifetime. "

Sir Paul Nurse, Cancer Research UK

Your research papers will be:

- available free of charge to the entire biomedical community

- peer reviewed and published immediately upon acceptance

- cited in PubMed and archived on PubMed Central

- yours - you keep the copyright
BioMedcentral 